\title{
Coxsackievirus A16 infection stimulates imbalances of $T$ cells in children
}

\author{
QINGMING LUO, WANJUN PENG and LI CHEN \\ Department of Pediatrics, Shilong People's Hospital, Dongguan, Guangdong 523320, P.R. China
}

Received March 26, 2014; Accepted October 9, 2014

DOI: $10.3892 /$ etm.2015.2405

\begin{abstract}
Immune reaction plays a crucial role in the regulation of the progression of Coxsackievirus A16 (CA16)-infected hand, foot and mouth disease (HFMD). However, no details of T-cell subset frequency or imbalance during the CA16 infection process have been revealed. In the present study, whether CA16-induced HFMD changes the frequency of different T-cell subsets and associated immune mediators was determined in children. The results indicate that the percentages of Th1 and Tc1 cells were significantly increased in children with HFMD compared with those in healthy children. In addition, the Th1/Th2 ratio and interferon (IFN) $-\gamma$ levels were significant higher in children with HFMD. Furthermore, the percentage of Th17 cells and the Th17/Treg ratio as well as interleukin (IL)-17A levels were higher in HFMD cases. In conclusion, the present study demonstrated the dysregulation of T-cell subsets following CA16 infection. The Th1/Th2 and Th17/Treg ratios were imbalanced following infection. Also, the imbalance Th1/Th2 and Th17/Treg ratios contributed to the increased levels of IFN- $\gamma$ and IL-17A. Based on this information, the present study provides new insights for the future study of CA16-induced HFMD and offers new data of diagnostic and therapeutic value for CA16 infection.
\end{abstract}

\section{Introduction}

Hand, foot, and mouth disease (HFMD) is a significant childhood illness. It is characterized by fever and vesicular eruptions on the hands, feet and mouth. Also, certain complications occur, although rarely, such as pneumonia, meningitis, rhabdomyolisis and encephalitis. The most common infective agents in HFMD are coxsackievirus A16 (CA16) and enterovirus 71 (EV71) (1). A large number of studies have focused on EV71-associated HFMD while less attention has been

Correspondence to: Dr Qingming Luo, Department of Pediatrics, Shilong People's Hospital, 1 Xianglong Road, Dongguan, Guangdong 523320, P.R. China

E-mail: luoqingxian1@126.com

Key words: hand, foot and mouth disease, Coxsackievirus A16, T-cell subsets, cytokines, imbalance paid to CA16 strains due to the mild and benign symptoms following infection $(1,2)$. Based on phyletic evolution analysis, CVA16 is closely related to EV71; however, the pathogenesis and symptoms may differ, which has not been fully determined (1). Since 2007, large-scale outbreaks of CA16 infection in China have occurred (3). Genetic diversities and the evolution of CA16 strains have been identified in several studies (2). A total of $42 \mathrm{CV} 16$ strains have been reported from different locations in China, including Inner Mongolia, Gansu, Qinghai and Shandong provinces (2). With the exception of strain identification, little information has been presented on the pathogenetic mechanisms. A previous study demonstrated that CA16 plays only a subsidiary role in the pathogenesis (4). Nevertheless, understanding the mechanism of the effects of CA16 is likely to aid therapeutic strategies for HFMD.

CV16 and EV71 share the same receptor, scavenger receptor class B member 2 (SCARB2) (5). By developing transgenic mice with expression of human SCARB2, Chang et al investigated the efficacy conferred by a neutralizing antibody, N3 (5). The results showed that accumulated viral loads and the expression of pro-inflammatory cytokines were positively correlated. The authors concluded that the neutralizing antibody, N3, could be used as a new potential therapy for treating severe HFMD. The immunological reactions following EV71 infection have been deeply studied. Changes in the expression levels of several inflammatory mediators following EV71 infection have been investigated, including interferon (IFN) $-\gamma$, interleukin (IL)-13, IL-6, IL-1 $\beta$ and IL-10, as well as chemokines IL-8 and IL-10 (6). The expression of these mediators was found to correlate with disease severity and outcome. In a mouse model, the mice with a lack of $\mathrm{CD}^{+}{ }^{+}$or $\mathrm{CD}^{+} \mathrm{T}$ cells had more severe disease (7). In addition, high expression levels of IL-6 were found in newborn mice following EV71 infection and resulted in tissue damage (8). Li et al reported that Th1/Th2 and Th17/Treg imbalances were observed following EV71 infection (9). These findings illustrate the importance of cellular immunity in the pathogenesis of HFMD. However, at present, the pathogenesis of CV16 remains unclear.

$\mathrm{T}$ cells, also named $\mathrm{T}$ lymphocytes, play a crucial role in immune regulation. Dependent upon the cluster of differentiation (CD) receptors that they express, these cells can be classified into $\mathrm{CD} 4^{+}$and $\mathrm{CD} 8^{+} \mathrm{T}$ cells $(10) . \mathrm{CD}^{+} \mathrm{T}$ cells include Th1, Th2, Th17 and Treg subsets whereas CD8 ${ }^{+} \mathrm{T}$ cells include Tc1, Tc2 and Tc17 subsets. Type 1 cytokines, such as IL-2, tumor necrosis factor (TNF)- $\alpha$ and IFN- $\gamma$, are secreted 
by Th1 and Tc1 cells while type 2 cytokines such as IL-4, IL-5 and IL-13 are secreted by Th2 and Tc 2 cells (11). Th17 and Tc17 cells secrete IL-17, while Treg cells are characterized by IL-10 and TGF- $\beta$ expression (12). This secretion specificity and the different kinds of $\mathrm{T}$ cell subsets are in balance under normal conditions; however, when organisms suffer from an infectious disease, the system becomes imbalanced. For example, following Staphylococcus aureus implant infection, the Th1/Th17 response increased while Th2/Treg also responded to chronic infection (13). In EV71-infected patients with HFMD, the percentages of Th1, Tc1 and Th17 cells were found to be increased, and the Th1/Th2 ratio and IL-17A and IFN- $\gamma$ levels were upregulated (9). These studies demonstrate the imbalance of inflammatory mediators and $\mathrm{T}$ cells in the pathogenesis of HFMD subsequent to EV71 infection. Also, they suggest that $\mathrm{T}$-cell subset imbalance has an important role in the pathogenesis of infection.

Studies concerning different T-cell subsets in CA16-induced HFMD are very limited compared with those on EV71-induced HFMD. As there is a lack of information concerning vaccines or drugs for the prevention of CA16 infection, an increased understanding of CA16 infection is likely to contribute to new therapeutic strategies. Thus, in the present study, to elucidate the changes in the balance of T-cell subsets associated with CA16 infection, the distribution of T-cell subsets as well as the mediator expression in these cells were detected. These data may provide new insights for future study and be of diagnostic and therapeutic value for CA16-induced HFMD.

\section{Materials and methods}

Clinical samples. Clinical samples were collected from the Department of Pediatrics, Shilong People's Hospital (Dongguan, China). CA16 infection was identified by reverse transcription quantitative polymerase chain reaction (RT-qPCR) of nucleic acids in throat swabs or stool specimens. In total, 100 CA16 infected children with HFMD (aged 0.2-6.1 years old) were enrolled in this study. All the samples were taken at the same time, which was 3 days from the appearance of HFMD symptoms. In addition, 30 healthy children with no symptoms of HFMD were enrolled as controls. The clinical collection was approved by the Ethics Committee of the Department of Pediatrics, Dongguan Shilong People's Hospital. In addition, informed consent was obtained from the parents or guardians of all the children that participated in the present study.

Sample preparation. Samples, including throat swabs and stool samples, were collected from the patients or control children and then stored at $-80^{\circ} \mathrm{C}$ until analyzed. Also, blood samples were collected and the lymphocytes were isolated according to the manufacturer's instruction (Lymphoprep ${ }^{\text {тм }}$; Axis-Shield, Oslo, Norway). Peripheral blood mononuclear cells (PBMCs) were suspended at density of $1 \times 10^{6}$ cells $/ \mathrm{ml}$ in RPMI-1640 (Gibco, Grand Island, NY, USA) with $10 \%$ fetal bovine serum (Gibco).

$R T$ - $q P C R$. The RNAs were extracted from throat swabs and stool specimens using a PureLink ${ }^{\circledR}$ Viral RNA/DNA Mini kit (Invitrogen Life Technologies, Carlsbad, CA, USA) according to the manufacturer's instructions. The detection of CA16 was conducted by RT-qPCR as described in a previous study by Xiao et al (14). In brief, the RT-PCR thermal profile consisted of: reverse transcription program $\left(50^{\circ} \mathrm{C}\right.$ for $\left.30 \mathrm{~min}\right)$, denaturation program $\left(95^{\circ} \mathrm{C}\right.$ for $\left.3 \mathrm{~min}\right)$ and amplification program repeated 40 times $\left(95^{\circ} \mathrm{C}\right.$ for $5 \mathrm{sec}, 60^{\circ} \mathrm{C}$ for $\left.40 \mathrm{sec}\right)$ and $\mathrm{FAM}$, VIC and CY5 fluorescence measurement at $60^{\circ} \mathrm{C}$. RT-qPCR was carried out on a ABI 7500 Real-Time PCR system (Applied Biosystems ${ }^{\circledR}$, Invitrogen Life Technologies) The primers (purchased from Sangon Biotech, Shanghai, China) were as follows: tumor necrosis factor (TNF)- $\gamma$ forward: 5'-TGGCTTAATTCTCTCGGAAACG-3', reverse: 5'-TTT TACATATGGGTCCTGGCAGTA-3' and probe: 5'-ATCTTG GCTTTTCAGCTCTGCATCGTTTT-3'; IL-4 forward: 5'-CCCTCTGTTCTTCCTGCTAGCA-3', reverse: 5'-CCT GTAAGGTGATATCGCACTTGT-3' and probe: 5'-TGCCGG CAACTTTGTCCACGG-3'; IL-17A forward: 5'-GGGCCT GGCTTCTGTCTGA-3', reverse: 5'-AAGTTCGTTCTG CCCCATCA-3' and probe: 5'-CAAGGCACCACACAACCCA GAAAGGA-3'; transforming growth factor (TGF)- $\alpha$ forward 5'-GCCATTCTGGGTACGTTGGT-3', reverse: 5'-TGATGG CCTGCTTCTTCTGA-3' and probe: 5'-CACGCTGTGAGC ATGCGGACCTC-3'.

Enzyme-linked immunosorbent assay (ELISA). In the present study, ELISA was used to detect the expression levels of IFN- $\gamma$, IL-4, IL-17A and TGF- $\alpha$ in plasma using IFN- $\gamma$, IL-4, IL-17A and TGF- $\alpha$ ELISA kits provided by R\&D Systems (Minneapolis, MN, USA). The assays were conducted according to the manufacturer's instructions. All samples were tested in three replicated assays.

Flow cytometric analysis. For the analysis of different subsets of $\mathrm{T}$ cells, the cell suspension was provoked by culture with $25 \mathrm{ng} / \mathrm{ml}$ phorbol 12-myristate 13 -acetate (Sigma-Aldrich, St. Louis, MO, USA) and $1 \mu \mathrm{g} / \mathrm{ml}$ ionomycin (Sigma-Aldrich,) at $37^{\circ} \mathrm{C}$ for $4 \mathrm{~h}$. Subsequently, the cells were incubated with polyclonal PerCP-Cy5.5-labeled goat anti-human and polyclonal FITC-labeled goat anti-human CD8 antibodies (Santa Cruz Biotechnology, Santa Cruz, CA, USA) for $20 \mathrm{~min}$ at $4^{\circ} \mathrm{C}$. For Treg cells, the cell suspension was incubated with a mixture of polyclonal FITC-labeled goat anti-human CD4 and polyclonal PE-labeled goat anti-human CD25 (Santa Cruz Biotechnology) for $20 \mathrm{~min}$ at $4^{\circ} \mathrm{C}$. Subsequently, the cells were incubated with polyclonal Alexa Fluor 647-labeled goat anti-human Foxp3 (Santa Cruz Biotechnology). After fixing and permeabilizing, the stained cells were assayed by an Epics XL-MCL flow cytometer (Beckman Coulter, Miami, FL, USA). The ratios of the cells were calculated by the antibody signals of the specific proteins. Isotype controls were used to correct compensation and confirm antibody specificity. All calculations were performed using EXPO32 ADC software (Beckman Coulter).

Statistic analysis. Statistical analysis was performed using SPSS software, version 13.0 (SPSS, Inc., Chicago, IL, USA). The significance of differences was determined by one-way analysis of variance (ANOVA). Differences were considered significantly if $\mathrm{P} \leq 0.05$. If $\mathrm{F}$ ratios exceeded the critical value 
Table I. Basic information of studied samples.

\begin{tabular}{lccc}
\hline Variables & Control & Mild & Severe \\
\hline Number of samples & 30 & 49 & 51 \\
Age (years) & $2.05 \pm 1.62$ & $2.31 \pm 1.54$ & $1.97 \pm 1.28$ \\
Gender (male/female) & $15 / 15$ & $24 / 25$ & $27 / 24$ \\
Length of hospitalization (days) & 0 & $6.00(4.00-7.00)$ & $9.00(7.00-11.00)^{\mathrm{a}}$ \\
Highest body temperature $\left({ }^{\circ} \mathrm{C}\right)$ & - & $38.42 \pm 0.88$ & $38.78 \pm 0.48$ \\
Fever duration (days) & - & $2.13 \pm 0.53$ & $4.53 \pm 0.62^{\mathrm{a}}$ \\
WBC (x10 $/ \mathrm{l})$ & $7.03(5.47-8.11)$ & $11.53(9.39-13.02)$ & $12.32(10.83-14.02)^{\mathrm{a}}$ \\
Neutrophil $(\%)$ & $59.35 \pm 8.63$ & $57.56 \pm 7.26$ & $60.23 \pm 4.69$ \\
CRP (mg/l) & - & $7.00(5.00-9.53)$ & $7.51(4.53-10.04)$ \\
CA16 (copies/ml) hroat swabs & 0 & $5 \times 10^{6}-4 \times 10^{7}$ & $5 \times 10^{8}-4 \times 10^{10 \mathrm{a}}$ \\
CA16 (copies/ml) stool & 0 & $3 \times 10^{4}-4 \times 10^{5}$ & $2 \times 10^{5}-7 \times 10^{8 \mathrm{a}}$ \\
\hline
\end{tabular}

WBC, white blood cell count; CRP, C-reactive protein; CA16, Coxsackievirus A16. ${ }^{a} \mathrm{P}<0.05$ vs. control.

A

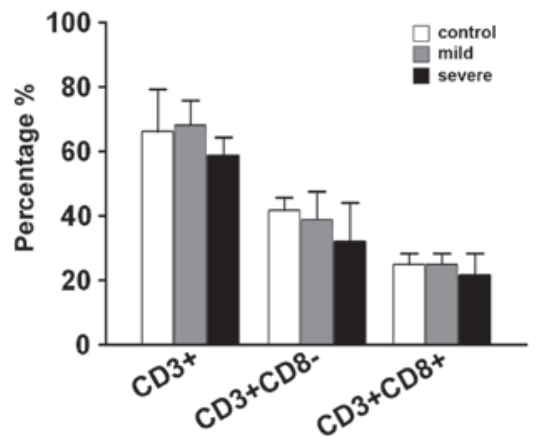

B

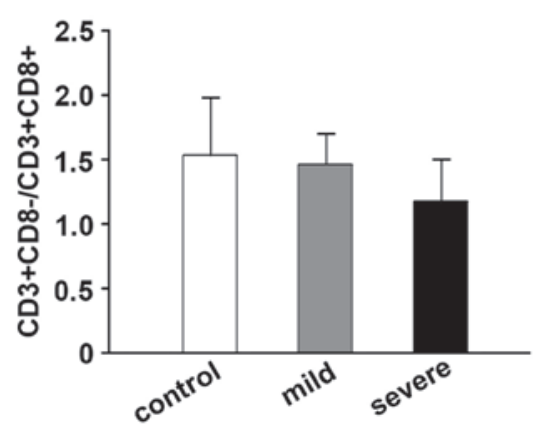

Figure 1. (A) Percentages of $\mathrm{CD}^{+}, \mathrm{CD}^{+}{ }^{+} \mathrm{CD} 8^{-}$and $\mathrm{CD} 3^{+} \mathrm{CD} 8^{+} \mathrm{T}$ cells and (B) the $\mathrm{CD}^{+} \mathrm{CD} 8 / \mathrm{CD}^{+} \mathrm{CD} 8^{+}$ratio among control children and children with mild and severe HFMD.

$(\mathrm{P} \leq 0.05)$, the Newman-Keul's post-hoc test was performed to compare the groups.

\section{Results}

Case overview. Of the 100 patients with HFMD, 49 and 51 patients were diagnosed with mild and severe HFMD, respectively, according to the diagnostic criteria described in a previous study (15). No significant differences in age and gender were identified among the studied groups. The duration of hospitalization and fever duration were significantly higher in the severe group compared with the control and mild groups. Among all 100 patients with HFMD, all cases were confirmed by RT-qPCR to be infected with CA16, and CA16 nucleic acid was detected in both throat swabs and stool specimens. The results showed that the severe group had the higher number of copies of CA16 in both throat swabs and stool species (Table I).

The percentages of different subsets of $\mathrm{T}$ cells in the control, mild HFMD and severe HFMD groups were assayed. The percentages of $\mathrm{CD}^{+} \mathrm{T}$ cells in the control, mild HFMD and severe HFMD groups were 67.32 \pm 12.52 , 70.03 \pm 7.37 and $58.92 \pm 8.74 \%$, respectively. The percentages of $\mathrm{CD}^{+} \mathrm{CD} 8-$ T cells in the control, mild HFMD and severe HFMD groups were $43.44 \pm 4.85,40.05 \pm 7.55$ and $37.22 \pm 13.24 \%$, respectively. The percentages of $\mathrm{CD}^{+} \mathrm{CD}^{+} \mathrm{T}$ cells in the control, mild HFMD and severe HFMD groups were $26.23 \pm 2.03,26.18 \pm 2.23$ and $19.63 \pm 4.03 \%$, respectively. Statistically, the percentages of these subsets of $\mathrm{T}$ cells were not significantly different among all the tested groups (Fig. 1A). The values of $\mathrm{CD}^{+}{ }^{+} \mathrm{CD} 8^{-}$and $\mathrm{CD}^{+} \mathrm{CD}^{+}$were used to calculate the $\mathrm{CD}^{+} \mathrm{CD}^{-} / \mathrm{CD}^{+} \mathrm{CD}^{+}$ ratio. This ratio also was not identified to differ significantly among the groups (Fig. 1B).

Imbalance of Th1, Th2, Tcl and Tc2 in CA16-infected patients. The percentages of Th1 cells were $6.12 \pm 2.05,18.52 \pm 1.98$ and $26.53 \pm 5.69 \%$ in the control, mild HFMD and severe HFMD groups, respectively. The Th1 percentage in each group was found to be significantly different compared with that in the other two groups (Fig. 2A). By contrast, no such difference was identified in the Th2 cell percentage (Fig. 2B). The Th1/Th2 ratio was significantly increased in the mild $(8.82 \pm 1.98)$ and severe groups $(11.52 \pm 28.92)$ compared with that in the control group $(0.93 \pm 1.02$; Fig. $2 \mathrm{C})$.

The Tc1 cell percentage was significantly higher in the mild $(42.35 \pm 4.52 \%)$ and severe $(58.68 \pm 11.37 \%)$ HFMD groups compared with that in the control group (18.52 $\pm 4.37 \%$; Fig. 2D). By contrast, the Tc2 cell percentage did not significantly differ among the groups (Fig. 2E). In a similar manner to the Th1/Th2 ratio, the $\mathrm{Tc} 1 / \mathrm{Tc} 2$ ratio was higher in the mild $(72.23 \pm 14.92)$ and severe HFMD groups 

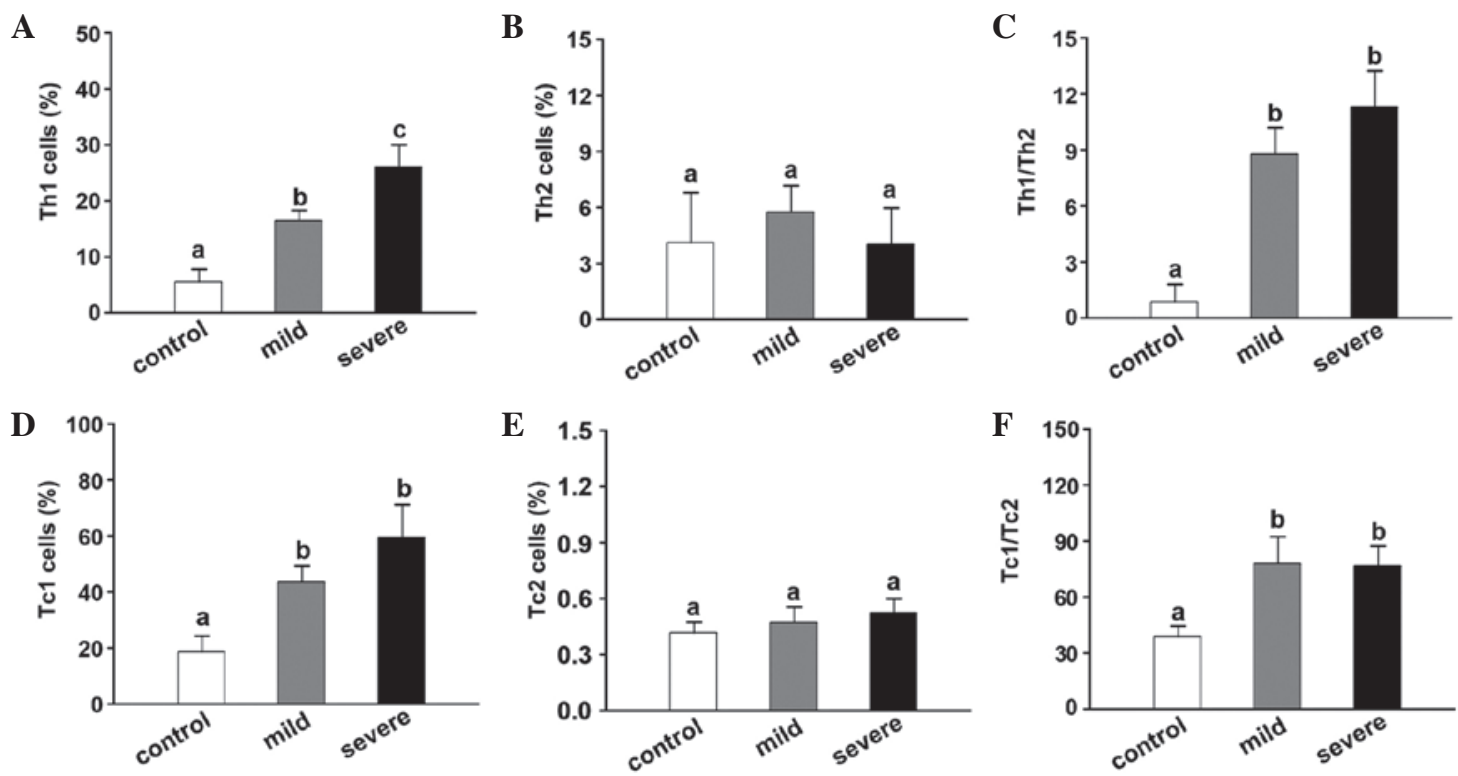

Figure 2. Percentage of Th1 (A), Th2 (B), Tc1 (D) and Tc2 (E) cells as well as the ratio of Th1/Th2 (C) and Tc1/Tc2 (F) in control, mild and severe HFMD children. Different characters showed significant difference $(\mathrm{P}<0.05)$ among the tested groups.

A

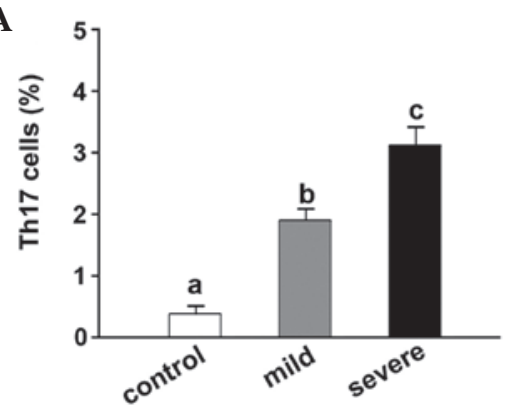

C

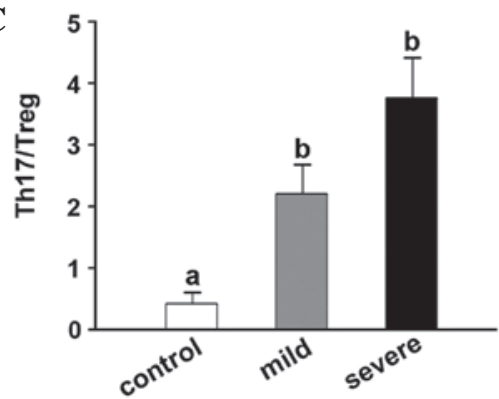

B

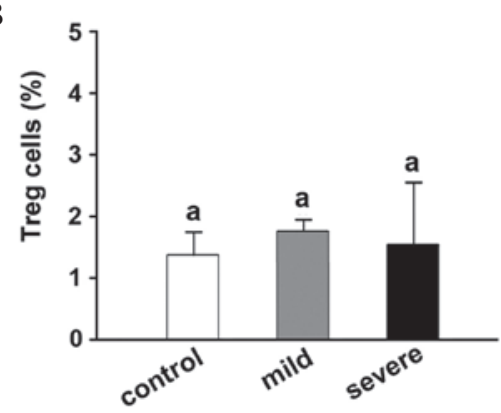

D

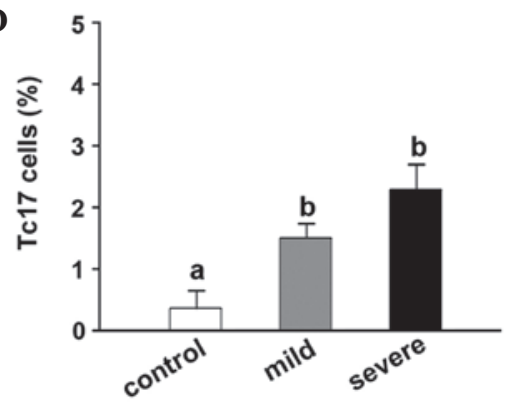

Figure 3. Percentage of Th17 (A), Treg (B) and Tc17 cells (D), as well as the ratio of Th17/Treg (C) in control, mild and severe HFMD children. Different characters showed significant difference $(\mathrm{P}<0.05)$ among the tested groups.

$(70.79 \pm 17.54)$ compared with that in the control group (41.13 \pm 5.89 ; Fig. 2F).

Disrupted balance of Th17/Treg in CA16-infected patients. The cell frequencies of Th17 were significant higher in the mild $(1.83 \pm 0.17 \%)$ and severe HFMD groups $(3.21 \pm 0.39 \%)$ than in the control group $(0.41 \pm 0.14 \%$; Fig. $3 \mathrm{~A})$, while the percentage of Treg cells was not identified to be significantly different among the groups (Fig. 3B). The Th17/Treg ratio was also found to be higher in the mild $(2.23 \pm 0.42)$ and severe HFMD groups $(3.76 \pm 0.72)$ compared with that in the control group

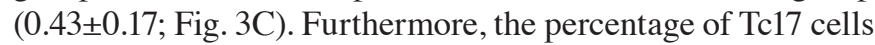

was also significantly higher in the mild $(1.73 \pm 0.14 \%)$ and severe HFMD groups $(2.35 \pm 0.54 \%)$ than in the control group

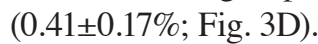

CA16 infection changes cytokine levels in plasma. The expression levels of immune mediators, specifically IFN- $\gamma$, IL-17A, IL- 4 and TGF- $\beta$ in plasma were determined by ELISA. The levels of IFN- $\gamma$ were significant higher in the mild $(11.03 \pm 0.75 \mathrm{pg} / \mathrm{ml})$ and severe $(12.14 \pm 1.49 \mathrm{pg} / \mathrm{ml})$ HFMD groups than in the control group $(1.06 \pm 0.25 \mathrm{pg} / \mathrm{ml}$; Fig. 4A). Similarly, IL-17A exhibited higher levels in the mild $(2.68 \pm 0.56 \mathrm{pg} / \mathrm{ml})$ and severe $(11.52 \pm 1.22 \mathrm{pg} / \mathrm{ml})$ HFMD groups compared with 
A

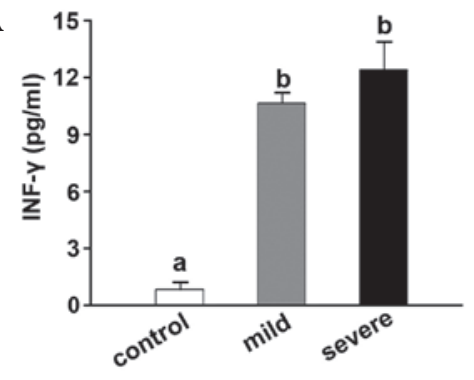

C

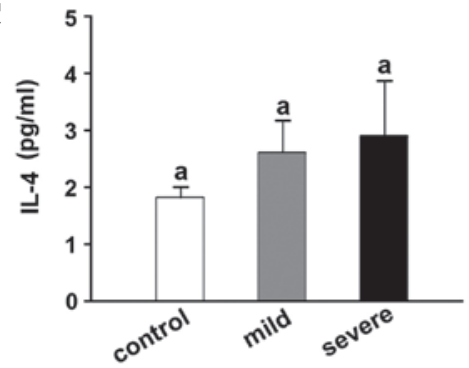

B
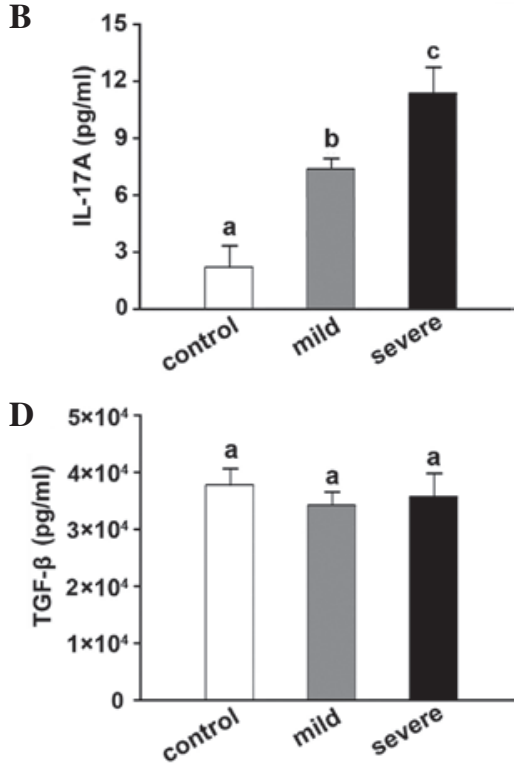

Figure 4. Plasma IFN- $\gamma$ (A), IL-4 (C), TGF- $\beta$ (D) and IL-17A (B) levels in plasma of control, mild and severe HFMD children based on ELISA assay. Different characters showed significant difference $(\mathrm{P}<0.05)$ among the tested groups.

that in the control group $(2.82 \pm 1.25 \mathrm{pg} / \mathrm{ml}$; Fig. 4B). However, the levels of IL-4 and TGF- $\beta$ were not identified to be significantly different among the three groups (Fig. 4C and D).

\section{Discussion}

At present, a significant amount of evidence indicates that inappropriate inflammation participates in the progression of HFMD $(11,13)$. However, when more mild and benign symptoms are present following infection, little information has been unveiled concerning the adaptive immunity of the infected host. In the present study, the T-cell profile and related immune mediators were analyzed in CA16-infected children with HFMD, in order to investigate the association between changes in T cells and HFMD. The results demonstrate that CA16-infected children had higher percentages of Th1, Th17, Tc1 and Tc17 cells as well as plasma IFN- $\gamma$ and IL-17A levels than healthy control children had. These results indicate that the immune system is disordered following CA16 infection. In concurrence with the present study, Li et al observed an imbalance of T-lymphocyte subsets with abnormal production of IFN- $\gamma$ and IL-17A following EV71 infection in children with HFMD (9). In addition, the EV71-related encephalitis was associated with a significant increase in the levels of pro-inflammatory cytokines, such as IL-6, TNF- $\alpha$ and IL- $1 \beta$. Together, these findings imply that HFMD-related infection, including EV71 and CA16 infection, contributes to dysregulation of the immune system.

So far, to the best of our knowledge, no information depicting the role of Th1 in CA16 infected HFMD patients has been published. Th1 cytokines have been shown to have a crucial role in the pathogenesis of EV71-infected HFMD (9). In the present study, it was demonstrated that there was no significant difference in Th2 and Tc2 percentages among the three groups, while IFN- $\gamma$ production by $\mathrm{T}$ cells (Th1 and Tc1) was significantly increased following CA16 infection. In addition, the $\mathrm{Th} 1 / \mathrm{Th} 2$ ratio was also shown to rise in children with HFMD. These results indicate the CA16 dysregulated the balance between Th1 and Th2, and suggest that CA16 infection in HFMD may associated with Th1-promoted disease.

The Th1/Th2 ratio hypothesis was proposed from research in 1986 suggesting that mouse T-helper cells expressed differing cytokine patterns (16). Th1 cells drive cellular immunity while Th2 cells drive humoral immunity. The Th1/Th2 ratio thus reflects the cellular/humoral immunity balance following pathogen invasion. The Th1/Th2 ratio clearly indicates immunological changes in mammalians. The Th1/Th2 ratio hypothesis explains cancer, diabetes and pathogenic infection well (17-19). However, the Th1/Th2 ratio hypothesis also demonstrates limitations in several diseases, including asthma, rheumatoid arthritis and chronic hepatitis B (19-21). In the present study, the Th1/Th2 balance was affected in children with HFMD. However, no significant difference could be observed in the Th1/Th2 ratio between patients with mild and severe HFMD. This shows a certain limitation of the Th1/Th2 balance theory in children with HFMD. Thus, changes in T-cell subsets participate in CA16-induced HFMD. Treg and Th17 cells have been identified to participate in multidirectional immunological reaction following Th1/Th2 balance changes $(22,23)$. The present study also revealed a change in the Th17 and Th17/Treg ratio that was associated with the disease severity. Based on these findings, the imbalance of Th1/Th2 cells may stimulated by HFMD, while the Th17/Treg imbalance may play a decisive function in HFMD progression. These findings are consistent with a previous study by Chen et al, which identified that Th17 cells increased significantly in children with HFMD, suggesting that Th17-mediated immune response plays a crucial role in the progression of HFMD (24). Notably, the percentage of Th17 cells was higher in the severe group compared with the mild group. Thus, it was also found that the level of IL-17A, which is secreted by Th17 cells, also increased. IL-17A is known to contribute to the inflammatory response and induces the production of several cytokines and chemokine mediators. As result, neutro- 
phil activation processes, such as differentiation, maturation and migration, are under the control of IL-17A (25). This is in accordance with the finding that the white blood cell count increased following CA16 infection in the children in the present study. Li et al demonstrated that Th17 cells and IL-17A are involved in the progression of EV71-related HFMD (9). Thus, these data suggest that changes in the levels of Th17 cells and increasing levels of IL-17A secretion are key factors in CA16-induced HFMD.

In contrast to the acute increase in the levels of Th17 cells and IL-17A in plasma, other inflammatory mediators such as IL-4 and TGF- $\beta$ showed no changes following CA16 infection. The percentage of Treg cells was also unchanged in children with HFMD. This also implies the importance of Th17 cell function in the pathogenesis of HFMD rather than the function of Treg cells.

In addition, no significant difference could be identified between mild and severe HFMD cases. These finding is comparable with the results in the studies by Yang et al (26) and Li et al (9). The authors demonstrated that the viral load of EV71 was not correlated with certain immune factors statistically, including IL-4 and TGF- $\beta$. These data suggest that the viral loads in throat swabs or stool specimens may not correlate with several T-cell subsets as well as the immune factors in plasma. Lin et al reported that the changes in T-cell subsets exhibited a tissue-specific profile (27). They confirmed that throat swab and stool specimens showed a reduced viral load of EV71 than the specific tissue that is the focus of infection, and thus are not adequate for diagnosis. Therefore, it would be interest to elucidate the precise tissue-specific profile of different T-cell subsets in CA16-induced HFMD in future studies.

In conclusion, the present study reported that a dysregulation of T-cell subsets occurs in CA16-induced HFMD, as well as imbalances in the Th1/Th2 and Th17/Treg ratios following infection. The imbalances contribute to increases in the levels of IFN- $\gamma$ and IL-17A accordingly. However, the molecular mechanisms of CA16-induced HFMD remain insufficiently understood. The present findings provide a new insight for future studies of CA16-induced HFMD, and provide information of diagnostic and therapeutic values for CA16 infection.

\section{References}

1. Iwai M, Masaki A, Hasegawa S, et al: Genetic changes of coxsackievirus A16 and enterovirus 71 isolated from hand, foot, and mouth disease patients in Toyama, Japan between 1981 and 2007. Jpn J Infect Dis 62: 254-259, 2009.

2. Zhang Y, Wang D, Yan D, et al: Molecular evidence of persistent epidemic and evolution of subgenotype B1 coxsackievirus A16-associated hand, foot, and mouth disease in China. J Clin Microbio 48: 619-622, 2010.

3. Ding NZ, Wang XM, Sun SW, Song Q, Li SN and He CQ: Appearance of mosaic enterovirus 71 in the 2008 outbreak of China. Virus Res 145: 157-161, 2009.

4. Liu LJ, Xu HM, Li XJ, et al: Co-detection in the pathogenesis of severe hand-foot-mouth disease. Arch Virol 157: 2219-2222, 2012.

5. Chang HW, Lin YW, Ho HM, et al: Protective efficacy of VP1-specific neutralizing antibody associated with a reduction of viral load and pro-inflammatory cytokines in human SCARB2-transgenic mice. PLoS One 8: e69858, 2013.
6. Wang SM, Lei HY, Huang MC, et al: Modulation of cytokine production by intravenous immunoglobulin in patients with enterovirus 71-associated brainstem encephalitis. J Clin Virol 37: 47-52, 2006.

7. Belkaid Y and Rouse BT: Natural regulatory T cells in infectious disease. Nat Immunol 6: 353-360, 2005.

8. Khong WX, Foo DG, Trasti SL, Tan EL and Alonso S: Sustained high levels of interleukin-6 contribute to the pathogenesis of enterovirus 71 in a neonate mouse model. J Virol 85: 3067-3076, 2011.

9. Li S, Cai C, Feng J, et al: Peripheral T lymphocyte subset imbalances in children with enterovirus 71-induced hand, foot and mouth disease. Virus Res 180: 84-91, 2014.

10. Gocinski BL and Tigelaar RE: Roles of CD4+ and CD8+ T cells in murine contact sensitivity revealed by in vivo monoclonal antibody depletion. J Immunol 144: 4121-4128, 1990.

11. Lucey DR, Clerici M and Shearer GM: Type 1 and type 2 cytokine dysregulation in human infectious, neoplastic, and inflammatory diseases. Clin Microbiol Rev 9: 532-562, 1996.

12. Jutel M, Akdis M, Budak F, et al: IL-10 and TGF- $\beta$ cooperate in the regulatory $\mathrm{T}$ cell response to mucosal allergens in normal immunity and specific immunotherapy. Eur J Immunol 33: 1205-1214, 2003.

13. Prabhakara R, Harro JM, Leid JG, Keegan AD, Prior ML and Shirtliff ME: Suppression of the inflammatory immune response prevents the development of chronic biofilm infection due to methicillin-resistant Staphylococcus aureus. Infect Immun 79: 5010-5018, 2011

14. Xiao XL, Wu H, Li YJ, et al: Simultaneous detection of enterovirus 70 and coxsackievirus A24 variant by multiplex real-time RT-PCR using an internal control. J Virol Methods 159: 23-28, 2009.

15. Ooi MH, Wong SC, Podin Y, et al: Human enterovirus 71 disease in Sarawak, Malaysia: a prospective clinical, virological, and molecular epidemiological study. Clin Infect Dis 44: 646-656, 2007.

16. Mosmann TR, Cherwinski H, Bond MW, Giedlin MA and Coffman RL: Two types of murine helper T cell clone. I. Definition according to profiles of lymphokine activities and secreted proteins. J Immunol 136: 2348-2357, 1986.

17. Myint AM, Leonard BE, Steinbusch HW and Kim YK: Th1, Th2, and Th3 cytokine alterations in major depression. J Affect Disord 88: 167-173, 2005.

18. Romagnani S, Maggi E and Del Prete G: An alternative view of the Th1/Th2 switch hypothesis in HIV infection. AIDS Res Hum Retroviruses 10: iii-ix, 1994.

19. Kuo ML, Huang JL, Yeh KW, Li PS and Hsieh KH: Evaluation of Th1/Th2 ratio and cytokine production profile during acute exacerbation and convalescence in asthmatic children. Ann Allergy Asthma Immunol 86: 272-276, 2001.

20. Okazaki K, Uchida K, Ohana M, et al: Autoimmune-related pancreatitis is associated with autoantibodies and a Th1/Th2-type cellular immune response. Gastroenterology 118: 573-581, 2000.

21. Taams LS, Palmer DB, Akbar AN, Robinson DS, Brown Z and Hawrylowicz CM: Regulatory T cells in human disease and their potential for therapeutic manipulation. Immunology 118: 1-9, 2006.

22. Weaver CT and Hatton RD: Interplay between the TH17 and TReg cell lineages: a (co-) evolutionary perspective. Nat Rev Immunol 9: 883-889, 2009.

23. Zhu J and Paul WE: Heterogeneity and plasticity of $\mathrm{T}$ helper cells. Cell Res 20: 4-12, 2010.

24. Chen J, Tong J, Liu H, et al: Increased frequency of Th17 cells in the peripheral blood of children infected with enterovirus 71. J Med Virol 84: 763-767, 2012.

25. Ley K, Smith E and Stark MA: IL-17A-producing neutrophil-regulatory Tn lymphocytes. Immunol Res 34: 229-242, 2006.

26. Yang X, Wu Q, Wen B, Dai H, Zhuang Y and Yang J: Prevalent characteristics in children with hand-foot-mouth disease in the Kunming area in 2010. Zhongguo Dang Dai Er Ke Za Zhi 14: 192-194, 2012 (In Chinese).

27. Lin YW, Chang KC, Kao CM, Chang SP, Tung YY and Chen SH: Lymphocyte and antibody responses reduce enterovirus 71 lethality in mice by decreasing tissue viral loads. J Virol 83: 6477-6483, 2009. 